\title{
BIT-ART: Multicentric Comparison of HDR-brachytherapy, Intensity-modulated Radiotherapy and Tomotherapy for Advanced Radiotherapy in Prostate Cancer
}

\author{
ANNA RITA ALITTO ${ }^{1}$, LUCA TAGLIAFERRI ${ }^{1}$, VALENTINA LANCELLOTTA ${ }^{1}$, ANDREA D’ AVIERO ${ }^{2}$, \\ ANTONIO PIRAS ${ }^{2}$, VINCENZO FRASCINO ${ }^{1}$, FRANCESCO CATUCCI $^{1}$, BRUNO FIONDA ${ }^{1}$, \\ CHRISTIAN STAACKMANN ${ }^{3}$, SIMONETTA SALDI $^{4}$, VINCENZO VALENTINI $^{1,2}$, \\ GYORGY KOVACS ${ }^{3,5}$, CYNTHIA ARISTEI $^{4}$ and GIOVANNA MANTINI ${ }^{1,2}$ \\ ${ }^{1}$ Fondazione Policlinico Universitario “A. Gemelli” IRCCS, Rome, Italy; \\ ${ }^{2}$ Università Cattolica del Sacro Cuore, Rome, Italy; \\ ${ }^{3}$ Interdisciplinary Brachytherapy Unit, University of Lübeck - University Hospital S-H, \\ Campus Lübeck, Lübeck, Germany; \\ ${ }^{4}$ Radiation Oncology Section, Department of Surgery and Biomedical Science, \\ University of Perugia, Perugia, Italy; \\ ${ }^{5}$ Università Cattolica del Sacro Cuore, Educational Program Director Gemelli-INTERACTS, Rome, Italy
}

\begin{abstract}
Background/Aim: The aim of the study was to evaluate acute and late genitourinary (GU) and gastrointestinal (GI) toxicity in patients with high-or intermediate-risk prostate cancer. Patients and Methods: We evaluated data of patients from three Radiation Oncology Departments (Rome, Lübeck and Perugia). Patients treated in Rome underwent exclusive intensity-modulatedradiotherapy (IMRT) or IMRT plus high-dose-rate interventional radiotherapy (HDR-IRT). IMRT plus two fractions HDR-IRT was performed in Lübeck, while in Perugia Helical Tomotherapy was performed. The Common Toxicity Criteria for Adverse Event (Version 4.03) scale was used to describe acute and late toxicity. Results: At a median follow-up of 28 months, all 51 patients were alive and disease-free. Patients treated by HDR-IRT plus VMAT showed only G1-2 genitourinary-gastrointestinal (GU-GI) acute and late toxicity. Univariate analysis showed a lower risk of acute $G U$ toxicity $(p=0.048)$ in IMRT+HDR-IRT. Conclusion: Low grade and less acute $G U$ toxicity was observed in patients undergoing HDR-IRT boost.
\end{abstract}

This article is freely accessible online.

Correspondence to: Valentina Lancellotta, Fondazione Policlinico Universitario “A. Gemelli" IRCCS, Rome, Italy. Tel: +39 0630154986, e-mail: valentina.lancellotta@policlinicogemelli.it

Key Words: Personalized medicine, prostate cancer, HDR brachytherapy, VMAT, helical tomotherapy, focal therapy, toxicity.
Prostate cancer is a common disease, accounting for an estimated $19 \%$ of men malignancies and $9 \%$ of male cancer deaths (1). Prostate cancer radiotherapy is delivered by external beam radiotherapy (EBRT) or brachytherapy (interventional radiotherapy, IRT, BT) as a monotherapy or as a combination of both procedures.

Local biochemical relapse continues to represent the main pattern of failure after standard treatment approaches and dose-escalation as a means of treatment intensification to improve biochemical and survival outcomes (2). Despite IRT plays an important role in the treatment of localized low-risk prostate cancer, it is not largely used $(3,4)$.

For intermediate- and high-risk disease, the best treatment of prostate cancer has not yet been defined, due to lack of well-designed randomized trials comparing different treatment modalities (4).

High-dose-rate (HDR) IRT has been shown to be associated with high radiation dose conformity within the target volume, rapid dose fall-off in adjacent organs at risk, relatively short treatment time, and excellent cosmetic and good functional outcomes (5-8).

The major advantage of HDR IRT, compared with external beam radiotherapy (EBRT), is its ability to overcome the organ motion and to spare the organs at risk (OARs), as well as the potential of biological planning (9-17). IRT as a boost in combination with EBRT may be the optimal solution in locally advanced cases since IRT alone may not adequately treat the peri-prostatic tissue $(15,18)$. Case series and randomized trials have shown that HDR boost complementary to external beam treatment provided good 
Table I. Patients features. Total number of patients $\left(n^{\circ}\right): 51$.

\begin{tabular}{|c|c|c|c|c|}
\hline Median age (years) & 74 & & & \\
\hline & Total & Lübeck & Rome & Perugia \\
\hline \multicolumn{5}{|l|}{ Stage $\left(n^{\circ}\right)$} \\
\hline cT1c & 1 & 1 & 0 & 0 \\
\hline cT2a & 1 & 0 & 1 & 0 \\
\hline $\mathrm{cT} 2 \mathrm{~b}$ & 10 & 4 & 0 & 6 \\
\hline $\mathrm{cT} 2 \mathrm{c}$ & 17 & 3 & 3 & 11 \\
\hline cT3a & 10 & 0 & 10 & 0 \\
\hline cT3b & 12 & 1 & 11 & 0 \\
\hline \multicolumn{5}{|l|}{ GS $\left(n^{\circ}\right)$} \\
\hline$<7$ & & 0 & 10 & 5 \\
\hline$>7$ & & 9 & 15 & 11 \\
\hline NK & & 0 & 0 & 1 \\
\hline \multicolumn{5}{|l|}{ Baseline PSA Value $\left(\mathrm{n}^{\circ}\right)$} \\
\hline$<10 \mathrm{ng} / \mathrm{ml}$ & & 5 & 16 & 2 \\
\hline$>10 \mathrm{ng} / \mathrm{ml}$ and $<20 \mathrm{ng} / \mathrm{ml}$ & & 2 & 7 & 2 \\
\hline$>20 \mathrm{ng} / \mathrm{ml}$ & & 2 & 2 & 13 \\
\hline \multicolumn{5}{|l|}{ Risk features $\left(\mathrm{n}^{\circ}\right)$} \\
\hline Intermediate - Risk & 28 & 6 & 5 & 17 \\
\hline High - Risk & 23 & 3 & 20 & 0 \\
\hline \multicolumn{5}{|l|}{ Basal uroflowmetry $\left(\mathrm{n}^{\circ}\right)$} \\
\hline Regular & 17 & 5 & 5 & 7 \\
\hline Reduction & 33 & 4 & 20 & 9 \\
\hline Pathological & 1 & 0 & 0 & 1 \\
\hline \multicolumn{5}{|l|}{$\operatorname{ADT}\left(\mathrm{n}^{\circ}\right)$} \\
\hline Pre-RT & 40 & 5 & 25 & 10 \\
\hline Only During-RT & 11 & 4 & 0 & 7 \\
\hline
\end{tabular}

ADT: Anti-androgen treatment; RT: radiotherapy.

results in terms of local control and survival $(16,18-22)$ such as in reduction of biochemical failure $(18,23)$.

In this multicentric study, we evaluated different treatment techniques with special focus on acute and late genitourinary (GU) and gastrointestinal (GI) toxicity outcomes in patients with prostate cancer treated by HDR-IRT plus intensitymodulated-radiotherapy (IMRT), comparing to patients treated by exclusive helical tomotherapy (HT) or exclusive IMRT.

\section{Patients and Methods}

The present comparative study consisted of three cohorts from three European radiation oncology departments (Rome, Lübeck and Perugia), to evaluate acute and late GU and GI toxicity after different kinds of dose escalation radiation therapy treatments.

Inclusion criteria. Selection criteria for this analysis were high-risk features (Stage T3 or Gleason Score $>7$ and/or prostate specificantigen level $>20 \mathrm{ng} / \mathrm{ml}$ ) or intermediate-risk features (Stage T2b/c and $\mathrm{GS}>7$ and/PSA $>10 \mathrm{ng} / \mathrm{ml}$ and $<20 \mathrm{ng} / \mathrm{ml}$ ), and no metastatic disease (cM0) (24). For patients who underwent HDR-IRT boost additional selection criteria were identified: no trans-urethral resection of the prostate (TURP) in the previous sixth months and
Table II. Treatment characteristics.

\begin{tabular}{|c|c|c|c|c|}
\hline Technique & Institution & $\begin{array}{c}\text { Dose } \\
\text { HDR-IRT }\end{array}$ & $\begin{array}{c}\text { Dose EBRT } \\
\text { (IMRT or HT) }\end{array}$ & $\begin{array}{l}\text { EqD2 total } \\
\text { prostate dose }\end{array}$ \\
\hline HDR Boost & Rome & $15 \mathrm{~Gy}$ in $1 \mathrm{fr}$ & $46 \mathrm{~Gy}$ in $23 \mathrm{fr}$ & $100 \mathrm{~Gy}$ \\
\hline +IMRT & Lübeck & $30 \mathrm{~Gy}$ in $2 \mathrm{fr}$ & $50 \mathrm{~Gy}$ in 25 & 158 Gy \\
\hline HT alone & Perugia & 0 & $\begin{array}{c}74.25 \text { Gy in } 33 \mathrm{fr} \\
\text { Or }\end{array}$ & 79,55-81 Gy \\
\hline IMRT alone & Rome & 0 & $\begin{array}{c}67.50 \mathrm{~Gy} \text { in } 25 \mathrm{fr} \\
80 \mathrm{~Gy} \text { in } 40 \mathrm{fr}\end{array}$ & 80 Gy \\
\hline
\end{tabular}

HDR-IRT: High-dose-rate interventional radiotherapy; EBRT: external beam radiotherapy; IMRT: intensity-modulated-radiotherapy; HT: helical tomotherapy; EqD2: equivalent dose to $2 \mathrm{~Gy} /$ fraction dose.

no anesthesiologic contraindications. Table I reports demographic and clinical features of patients.

Work-up. In all institutions, pre-treatment work-up included magnetic resonance (MRI) staging, clinical evaluation, basal uroflowmetry, testosterone and initial PSA evaluation $(3,25-27)$. No patients underwent surgery. Local recurrence was detected by multiparametric magnetic MRI (mpMRI) or MRI with endorectal coil and choline positron emission tomography-computed tomography (PET-CT) or CT scans when post-treatment PSA levels exceeded 1 $\mathrm{ng} / \mathrm{ml}$. A total of 49 patients $(96 \%)$ received androgen deprivation therapy (ADT) $(26,28)$.

Protocols. Patients treated in Rome at Gemelli ART (Advanced Radiation Therapy) Department - IOC (Interventional Oncology Center) underwent IRT alone or IRT complementary to IMRT. Exclusive IMRT was performed in 40 daily fractions for a total dose of 80 Gy to whole prostate and 72 Gy delivered to seminal vesicles or seminal vesicles' bases, according tumor stage. Combined EBRT+IRT treatment was performed with one fraction of HDR. The total dose was $15 \mathrm{~Gy}$ on the high-risk zone (peripheral zone) during a one- or two-nights hospitalization. Under spinal anesthesia, an intraoperative pre-planning was performed, in order to identify the optimal implant geometry. The definitive Trans-Rectal Ultra Sound (TRUS)-based treatment planning was realized after completing the implant in the bunker. Two weeks after IRT, all patients received EBRT (46 Gy in 23 daily fractions), by IMRT resulting in EQD2 $100 \mathrm{~Gy}$ total dose (assessing prostate alpha/beta $\alpha / \beta$ ratio at 1.5) (29) and a total treatment time of 8 weeks.

Patients treated in Lubeck underwent two fractions of HDR-BT, the total dose per fraction was 15 Gy plus IMRT $50 \mathrm{~Gy}$, resulting in a total nominal dose of $80 \mathrm{~Gy}$ (EQD2 $158 \mathrm{~Gy}$ ) in six weeks total treatment time. Real time biological (mpTRUS) online planning based focal dose escalation was practiced.

In Perugia, HT treatment was performed. The total dose delivered to whole prostate was 74.25 Gy in 33 daily fractions or $67.50 \mathrm{~Gy}$ in 25 daily fractions (EQD2 79.55-81 Gy) and 62 Gy or 56.25 Gy delivered to seminal vesicles. The treatment characteristics are reported in Table II.

Clinic visits occurred every 4 months for the first year, every 6 months for the next 4 years and annually thereafter. Acute and late toxicity were reported according to the Common Toxicity Criteria 

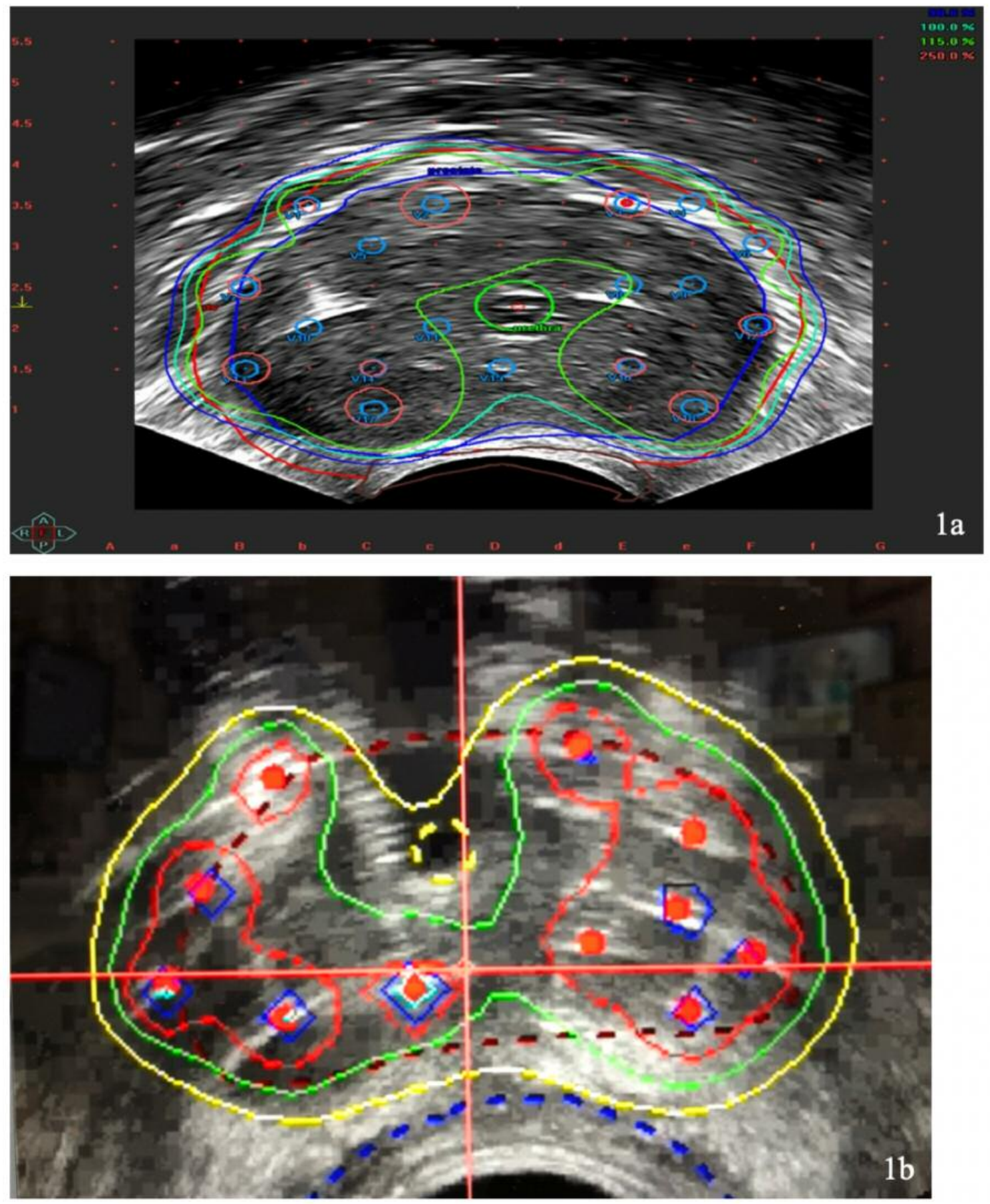

Figure 1. Dose distribution of HDR-IRT (Rome 1a) and biological planning (Luebeck 1b). Axial views show high conformality of HDR-IRT. a) Isodose lines: Cyan 15.0 Gy-Green 17.25 Gy-Red 37.5 Gy. b) Isodose lines: Yellow 7.5 Gy - Green 10.00 Gy - Red 15.0 Gy-Blue 30.0 Gy.

for Adverse Event (CTCAE Version 4.03) by the National Cancer Institute (30).

Statistical analysis. Prognostic factors i.e. age ( $\leq 75$ years old $v s$. $>75$ years old), class of risk (intermediate risk $v s$ high risk), ADT (yes $v s$. no), RT techniques (HT vs. VMAT vs. VMAT+BT) and uroflowmetry parameters (regular $v s$ pathological parameters) were analyzed using descriptive statistics.

Categorical data were analysed by the chi-square or Fisher exact test. Two-tailed $p<0.05$ was considered significant. All calculations were performed with IBM-SPSS ${ }^{\circledR}$, version 25.0, (IBM Corp., Armonk, NY, USA). 


\section{Results}

Data of fifty-one patients (23 with intermediate-risk and 28 with high-risk features) treated from July 2013 to August 2016 were evaluated.

EBRT treatment was performed in 34 patients, of whom 17 patients were treated by hypofractionated HT in Perugia and 17 patients underwent exclusive EBRT treatment with IMRT technique in Rome. HDR- IRT boost was performed in 17 patients, 8 in Rome and 9 in Lübeck (Table II). Three examples of dose distribution of HDR-BT (Figure 1A and B), HT (Figure 2) and IMRT (Figure 3A and B) are reported. Forty patients $(78 \%)$ received neo-adjuvant, concomitant and adjuvant ADT; 11 patients (22\%) received only adjuvant ADT.

Reduced uroflowmetry parameters before treatment were observed in 32/51 patients (62\%).

The mean follow-up (FU) time of the entire cohort was 28 months (range $=6-50$ months). All patients are alive. None had local or biochemical recurrence.

Grade 1-2 acute GU toxicity occurred in 7 patients treated by combined HDR boost and IMRT, 10 patients treated by IMRT alone, and 11 patients treated by HT. Grade 1-2 acute GI toxicity was observed in 4 patients treated by combined IRT+IMRT, 6 patients treated by HT and 8 patients treated by IMRT.

No GU Late Grade 2-3-4 toxicities were reported; GU G1 toxicity was observed in two patients treated by combined technique (IRT+IMRT) and in one patient treated by exclusive IMRT.

One patient treated by IMRT alone showed G1 GI late toxicity; no G2-3 GI late toxicity was observed (Table III).

Univariate analysis indicated a lower risk of acute GU toxicity by the use of IMRT+IRT ( $p=0.048$ ).

None of the other analyzed factors (age, class of risk) showed a significant impact on toxicities outcomes.

\section{Discussion}

In prostate cancer, biochemical relapse still represents the main site of failure after standard treatment approaches and dose-escalation as a means of treatment intensification improves biochemical and survival outcomes.

This study was designed to be a preliminary hypothesis generating analysis, investigating the feasibility of combined dose-escalation treatment approaches (EBRT alone versus EBRT combined with a boost of HDR-IRT, including biological planning at IRT) in intermediate- and high-risk localized prostate cancer patients evaluating toxicities outcomes.

Some previous retrospective analyses or randomized trials have compared outcomes in conventionally fractionated or hypo-fractionated EBRT as monotherapy with treatments including an IRT boost.

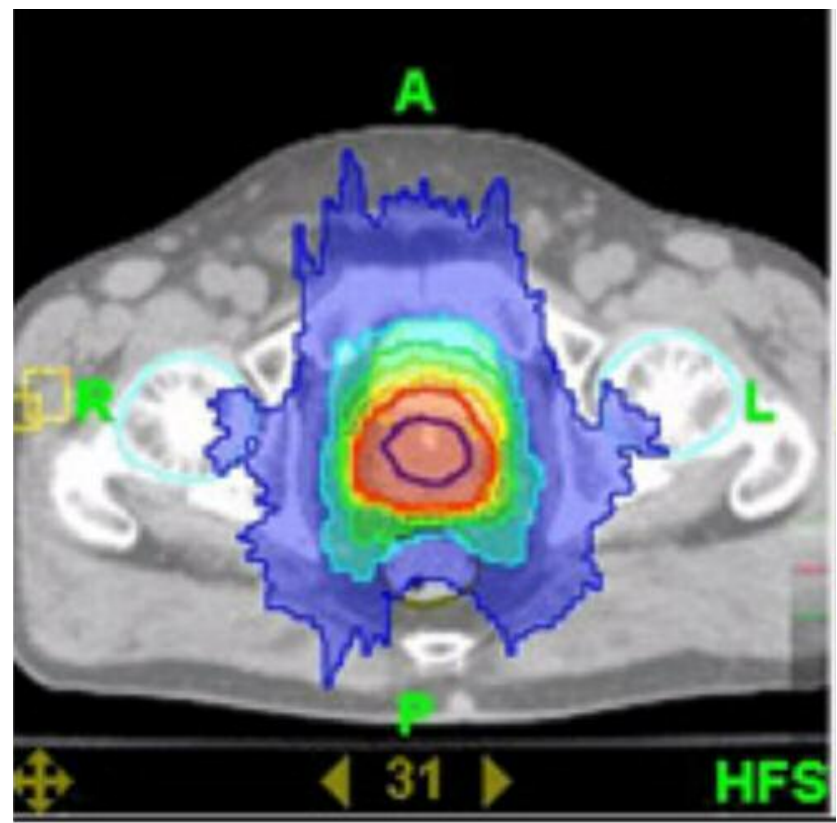

Figure 2. Dose distribution of helical tomotherapy (HT). Axial views show dose distribution relative to HT planning target volumes (PTVs) and organs at risk (Perugia).

The literature data $(13,15,16)$ has reported a statistically significant benefit in terms of biochemical disease-free survival in favor of the EBRT combined with BT.

Furthermore, in several investigations focal dose escalation based on biological imaging was found practical in reducing dose on OARs and non-dominant prostate target volumes (31-35). The existing high level of evidence (Level I, Group 1) presenting the superiority of HDR brachytherapy boost complementary to external beam boost (11) raised the question if mpTRUS is eligible for intraprocedural definition of relevant dominant (high Gleason) subvolumes within the prostate. Controlled investigations stated the equality of mpTRUS with mpMRI $(36,37)$; however, prospective randomized clinical trials are needed in the future.

In the presented analysis of different kind of dose escalation (EQD2: 79-158 Gy) treatments, we observed an advantage, in terms of acute GU toxicity outcomes, of the combination EBRT+IRT independently from the EBRT fractionation as only Grade 1-2 acute GU toxicity occurred.

Toxicity outcomes and quality of life (QoL) scores in patients undergoing HDR-IRT boost in prostate cancer has widely been assessed $(13,16,18,19,21,25)$. Hoskin et al. (15) randomized 220 patients to receive either hypofractionated EBRT alone or combined hypofractionated EBRT+HDR-IRT boost. The results showed no significant differences in terms of GU and GI toxicities among the two 
Table III. Toxicity (CTAE v4.03), IMRT+IRT had a lower risk of acute GU toxicity.

\begin{tabular}{|c|c|c|c|c|c|c|c|c|c|}
\hline & \multicolumn{3}{|c|}{ Tomotherapy } & \multicolumn{3}{|c|}{ VMAT } & \multicolumn{3}{|c|}{ VMAT+HDR-IRT } \\
\hline & G1 & G2 & G3 & G1 & $\mathrm{G} 2$ & G3 & G1 & G2 & G3 \\
\hline \multicolumn{10}{|l|}{ GU Acute } \\
\hline$p=0.048$ & 7 & 4 & 0 & 9 & 1 & 0 & 6 & 1 & 0 \\
\hline GU Late & 0 & 0 & 0 & 1 & 0 & 0 & 2 & 0 & 0 \\
\hline GI Acute & 4 & 2 & 0 & 6 & 2 & 0 & 4 & 0 & 0 \\
\hline GI Late & 0 & 0 & 0 & 1 & 0 & 0 & 0 & 0 & 0 \\
\hline
\end{tabular}

CTAE: Common Toxicity Criteria for Adverse Event; GU: genitourinary; GI: gastrointestinal; G: grade; IMRT: intensity-modulated-radiotherapy; HDRIRT: high dose-rate interventional radiotherapy.
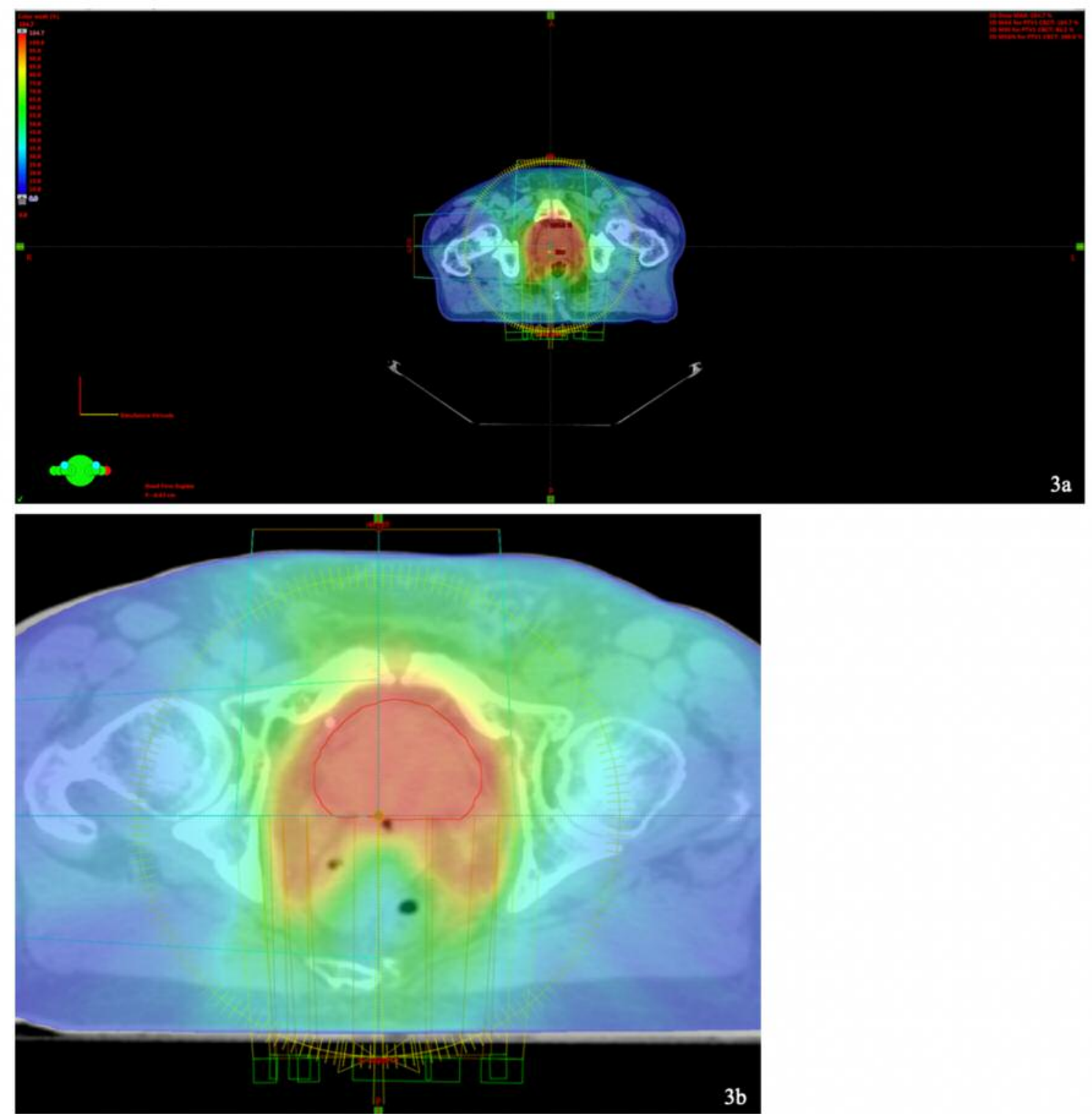

Figure 3. Dose distribution of intensity modulated radiotherapy (IMRT). Axial views show dose distribution relative to IMRT planning target volumes (PTVs) and organs at risk (Rome $3 a$ and Luebeck $3 b)$. 
groups. Sathya et al. (21) randomized 104 patients with nonmetastatic prostate cancer to either conventionally fractionated EBRT or IRT boost with conventionally fractionated EBRT. The authors reported no differences in the toxicity profile between the two arms. No studies compared different fractionation methods in the EBRT arms.

Compared to the Hoskin and Sathya studies, the present univariate analysis showed that IMRT+IRT had a lower risk of acute $\mathrm{GU}$ toxicity $(p=0.048)$ while no significant differences in acute and late GI and late GU were detected. HDR-IRT boost was not related to late G2-3 GU and GI toxicities showing that the combined treatment doseescalation could represent a valid option in intermediatehigh-risk prostate cancer treatment.

In another study, Morris randomized 398 patients with intermediate- and high-risk prostate cancer to either EBRT or low dose-rate (LDR) IRT complementary to EBRT. Assessment of the 5-year cumulative incidence of late grade 3 or higher toxicities detected a significant benefit in grade $3 \mathrm{GU}$ effects in favor of treatment with EBRT $(p=0.001)$ (20). Prestidge et al. in 2016, randomized 588 patients with low-intermediate risk prostate cancer to EBRT with LDR boost or LDR alone. There were no differences in acute grade 3 or higher toxicity but worse grade 3 or higher late toxicity in the IRT boost arm (22).

A recent systematic review of literature evidence on HDR IRT boost in prostate cancer showed good results in terms of toxicity outcomes and survival (18). Five years rate of LR (0-8\%) and OS (85-100\%) were shown among low-, intermediate-, high-risk, locally advanced prostate cancer patient groups. In terms of toxicity, less than 6\% Grade 3-4 late GU and GI toxicities were reported.

The differences in toxicity between these studies, but also between the IRT procedures (LDR $v s$. HDR) may be due to the ability to sparing the membranous urethra, which is associated with lower stricture rate. Using IRT it is possible to avoid patient and internal organ motion errors in treatment delivery also with the only expansion of $2 \mathrm{~mm}$ from clinical target volume (CTV) to planning target volume (PTV). The high-dose PTV in HDR-IRT is significantly smaller compared to that in EBRT (38-41).

Most trials used questionnaires to evaluate GU toxicity but it might be influenced by both patient and physician bias. However, patient reported outcomes are becoming crucial in treatment choice (42).

Our results confirmed the feasibility and safety of HDR boost escalation as shown in literature in other patient settings (43-45); even if HDR has to be performed in specialized centers collecting high numbers of patients with Expert Interventional Radiation Oncologist (46, 47).

However, in the present analysis, the small sample and the retrospective nature of the study reflect the difficulty to match patients in multi-institutional cohorts. Although the dose for each treatment was similar, we compared two different EBRT techniques that could reflect different conformity of fields.

In this scenario, advances in technologies and treatments for prostate cancer but also the huge heterogeneity of tumours and patients, need to consider a lot of different variables in the decision-making process (48).

Optimal treatment for prostate cancer has to be defined according to risk assessment; nomograms and predictive models can be used in order to help treatment decisionmaking. Nomograms offer more accurate prediction of treatment outcomes than simple risk group analyses because of the combination of relevant prognostic variables (49).

Many studies focused on the possibility of using predictive models not only for clinical outcomes, but also for toxicity occurrence $(50,51)$.

The above-mentioned results should also emphasize the need to combine analysis of treatment results from different centers in large databases in order to create predictive models $(52,53)$.

\section{Conclusion}

This preliminary study encourages the use of HDR-IRT as a local boost in dose escalated schedules for the radical treatment of intermediate- and high-risk prostate cancer. Less acute GU toxicity was observed in patients undergoing HDR-IRT boost even if focal ultra-high-dose (50 Gy IMRT+2×15 Gy HDR-IRT boost resulting in EQD2 $158 \mathrm{~Gy}$ ) was applied.

These findings support the hypothesis that focal ultra-high dose escalation is possible with IMRT+HDR-IRT if biological planning was performed.

Moreover, tolerance in HDR-IRT boost plus IMRT appeared to be comparable to exclusive IMRT and HT, while we need a longer follow-up to confirm the excellent results even in terms of survival outcomes.

A longer observation of this retrospective cohort and prospective data collection are desirable to confirm these preliminary results.

\section{Conflicts of Interest}

The Authors have declared no conflicts of interest regarding this study.

\section{Authors' Contributions}

Conception and design: Vincenzo Valentini, György Kovács, Cynthia Aristei and Giovanna Mantini; Data Collection: Andrea D'Aviero, Antonio Piras, Christian Staackmann, Simonetta Saldi; Analysis and interpretation of data: Vincenzo Frascino, Francesco Catucci, Bruno Fionda; Manuscript Writing: Anna Rita Alitto, Luca Tagliaferri, Valentina Lancellotta. 


\section{References}

1 Siegel RL, Miller KD and Jemal A: Cancer statistics, 2019. CA Cancer J Clin 69(1): 7-34, 2019. PMID: 30620402. DOI: $10.3322 /$ caac. 21551

2 Kuban DA, Tucker SL, Dong L, Starkschall G, Huang EH, Cheung MR, Lee AK and Pollack A: Long-term results of the M. D. Anderson randomized dose-escalation trial for prostate cancer. Int J Radiat Oncol Biol Phys 70(1): 67-74, 2008. PMID: 17765406. DOI: 10.1016/j.ijrobp.2007.06.054

3 Autorino R, Vicenzi L, Tagliaferri L, Soatti C, Kovacs G and Aristei $C$ : A national survey of airo (italian association of radiation oncology) brachytherapy (interventional radiotherapy) study group. J Contemp Brachytherapy 10(3): 254-259, 2018 PMID: 30038646. DOI: 10.5114/jcb.2018.76981

4 Mohler JL, Antonarakis ES, Armstrong AJ, D'Amico AV, Davis BJ, Dorff T, Eastham JA, Enke CA, Farrington TA, Higano CS, Horwitz EM, Hurwitz M, Ippolito JE, Kane CJ, Kuettel MR, Lang JM, McKenney J, Netto G, Penson DF, Plimack ER, PowSang JM, Pugh TJ, Richey S, Roach M, Rosenfeld S, Schaeffer E, Shabsigh A, Small EJ, Spratt DE, Srinivas S, Tward J, Shead DA and Freedman-Cass DA: Prostate Cancer, Version 2.2019, NCCN Clinical Practice Guidelines in Oncology. J Natl Compr Canc Netw 17(5): 479-505, 2019. PMID: 31085757. DOI: 10.6004/jncen.2019.0023

5 Hoskin PJ, Colombo A, Henry A, Niehoff P, Paulsen Hellebust T, Siebert F-A and Kovacs G: Gec/estro recommendations on high dose rate afterloading brachytherapy for localised prostate cancer: An update. Radiother Oncol 107(3): 325-332, 2013. PMID: 23773409. DOI: 10.1016/j.radonc.2013.05.002

6 Lancellotta V, Gyoergy K, Luca T, Elisabetta P, Agata R, Luca S, Marta T, Katharina H, Giuseppe C, Simonetta S, Vincenzo V and Cynthia A: The role of personalized interventional radiotherapy (brachytherapy) in the management of older patients with nonmelanoma skin cancer. J Geriatr Oncol 10(3): 514-517, 2019. PMID: 30314955. DOI: 10.1016/j.jgo.2018.09.009

7 Aristei C, Maranzano E, Lancellotta V, Chirico L, Zucchetti C, Italiani M, Anselmo P, Mariucci C, Perrucci E, Arcidiacono F, Trippa F, Kovacs G, Bini V and Palumbo I: Partial breast irradiation with interstitial multi-catheter high-dose-rate brachytherapy. Long-term results of a phase ii prospective study. Radiother Oncol 124(2): 208-213, 2017. PMID: 28764924. DOI: 10.1016/j.radonc.2017.07.015

8 Lancellotta V, Kovács G, Tagliaferri L, Perrucci E, Colloca G, Valentini $\mathrm{V}$ and Aristei $\mathrm{C}$ : Age is not a limiting factor in interventional radiotherapy (brachytherapy) for patients with localized cancer. BioMed Res Int 2018: 1-10, 2018. PMID: 29581964. DOI: $10.1155 / 2018 / 2178469$

9 Hoskin PJ, Bownes PJ, Ostler P, Walker K and Bryant L: High dose rate afterloading brachytherapy for prostate cancer: Catheter and gland movement between fractions. Radiother Oncol 68(3): 285-288, 2003. PMID: 13129636. DOI: 10.1016/S0167-8140(03)00203-2

10 Morton GC: The emerging role of high-dose-rate brachytherapy for prostate cancer. Clin Oncol 17(4): 219-227, 2005. PMID: 15997914. DOI: 10.1016/j.clon.2004.12.005

11 Martinez AA, Gonzalez J, Ye H, Ghilezan M, Shetty S, Kernen K, Gustafson G, Krauss D, Vicini F and Kestin L: Dose escalation improves cancer-related events at 10 years for intermediate- and high-risk prostate cancer patients treated with hypofractionated high-dose-rate boost and external beam radiotherapy. Int J Radiat Oncol Phys 79(2): 363-370, 2011. PMID: 21195875. DOI: 10.1016/j.ijrobp.2009.10.035

12 Koukourakis G, Kelekis N, Armonis V and Kouloulias V: Brachytherapy for prostate cancer: A systematic review. Adv Urol 2009: 1-11, 2009. PMID: 19730753. DOI: 10.1155/ 2009/327945

13 Yoshioka Y, Konishi K, Oh R-J, Sumida I, Yamazaki H, Nakamura S, Nishimura K, Nonomura N, Okuyama A and Inoue T: High-dose-rate brachytherapy without external beam irradiation for locally advanced prostate cancer. Radiother Oncol 80(1): 62-68, 2006. PMID: 16870289. DOI: 10.1016/j.radonc. 2006.06.011

14 Kovács G, Melchert C, Sommerauer M and Walden O: Intensity modulated high-dose-rate brachytherapy boost complementary to external beam radiation for intermediate- and high-risk localized prostate cancer patients - how we do it in lübeck/germany. Brachytherapy 6(2): 142-148, 2007. PMID: 17434108. DOI: 10.1016/j.brachy.2007.02.062

15 Hoskin PJ, Rojas AM, Bownes PJ, Lowe GJ, Ostler PJ and Bryant L: Randomised trial of external beam radiotherapy alone or combined with high-dose-rate brachytherapy boost for localised prostate cancer. Radiother Oncol 103(2): 217-222, 2012. PMID: 22341794. DOI: 10.1016/j.radonc.2012.01.007

16 Kovács G, Müller K, Soror T, Melchert C, Guo X, Jocham D and Merseburger A: Results of multiparametric transrectal ultrasound-based focal high-dose-rate dose escalation combined with supplementary external beam irradiation in intermediateand high-risk localized prostate cancer patients. Brachytherapy 16(2): 277-281, 2017. PMID: 27964906. DOI: 10.1016/j.brachy. 2016.11.005

17 Bisello S, Buwenge M, Palloni A, Autorino R, Cellini F, Macchia G, Deodato F, Cilla S, Brandi G, Tagliaferri L, Cammelli S, Valentini V, Morganti AG and Mattiucci GC: Radiotherapy or chemoradiation in unresectable biliary cancer: A retrospective study. Anticancer Res 39(6): 3095-3100, 2019. PMID: 31177154. DOI: 10.21873/anticanres.13445

18 Kee DLC, Gal J, Falk AT, Schiappa R, Chand M-E, Gautier M, Doyen J and Hannoun-levi J-M: Brachytherapy versus external beam radiotherapy boost for prostate cancer: Systematic review with meta-analysis of randomized trials. Cancer Treat Rev 70: 265 271, 2018. PMID: 30326422. DOI: 10.1016/j.ctrv.2018.10.004

19 Morton GC, Loblaw DA, Chung H, Tsang G, Sankreacha R, Deabreu A, Zhang L, Mamedov A, Cheung P, Batchelar D, Danjoux C and Szumacher E: Health-related quality of life after single-fraction high-dose-rate brachytherapy and hypofractionated external beam radiotherapy for prostate cancer. Int J Radiat Oncol Phys 80(5): 1299-1305, 2011. PMID: 20708853. DOI: 10.1016/j.ijrobp.2010.04.046

20 Morris WJ, Tyldesley S, Rodda S, Halperin R, Pai H, McKenzie M, Duncan G, Morton G, Hamm J and Murray N: Androgen suppression combined with elective nodal and dose escalated radiation therapy (the ascende-rt trial): An analysis of survival endpoints for a randomized trial comparing a low-dose-rate brachytherapy boost to a dose-escalated external beam boost for high- and intermediate-risk prostate cancer. Int J Radiat Oncol Phys 98(2): 275-285, 2017. PMID: 28262473. DOI: 10.1016/ j.ijrobp.2016.11.026

21 Sathya JR, Davis IR, Julian JA, Guo Q, Daya D, Dayes IS, Lukka HR and Levine M: Randomized trial comparing iridium 
implant plus external-beam radiation therapy with external-beam radiation therapy alone in node-negative locally advanced cancer of the prostate. Journal of Clin Oncol 23(6): 1192-1199, 2005. PMID: 15718316. DOI: 10.1200/JCO.2005.06.154

22 Prestidge BR, Winter K, Sanda MG, Amin M, Bice WS, Michalski J, Ibbott GS, Crook JM, Catton CN, Gay HA, Donavanik V, Beyer DC, Frank SJ, Papagikos MA, Rosenthal SA, Barthold HJJ, Roach M and Sandler HM: Initial report of nrg oncology/rtog 0232: A phase 3 study comparing combined external beam radiation and transperineal interstitial permanent brachytherapy with brachytherapy alone for selected patients with intermediate-risk prostatic carcinoma. Int J Radiat Oncol Phys 96(2): S4, 2016. DOI: 10.1016/j.ijrobp.2016.06.026

23 Wedde TB, Småstuen MC, Brabrand S, Fosså SD, Kaasa S, Tafjord G, Russnes KM, Hellebust TP and Lilleby W: Ten-year survival after high-dose-rate brachytherapy combined with external beam radiation therapy in high-risk prostate cancer: A comparison with the norwegian spcg-7 cohort. Radiother Oncol 132: 211-217, 2019. PMID: 30389241. DOI: 10.1016/j.radonc.2018.10.013

24 D'Amico AV, Whittington R, Malkowicz SB, Cote K, Loffredo M, Schultz D, Chen MH, Tomaszewski JE, Renshaw AA, Wein A and Richie JP: Biochemical outcome after radical prostatectomy or external beam radiation therapy for patients with clinically localized prostate carcinoma in the prostate specific antigen era. Cancer 95(2): 281-286, 2002. PMID: 12124827. DOI: $10.1002 /$ cncr.10657

25 Kovács G, Pötter R, Loch T, Hammer J, Kolkman-Deurloo I-K, de la Rosette JJMCH and Bertermann H: Gec/estro-eau recommendations on temporary brachytherapy using stepping sources for localised prostate cancer. Radiother Oncol 74(2): 137148, 2005. PMID: 15734201. DOI: 10.1016/j.radonc.2004.09.004

26 Mantini G, Siepe G, Alitto AR, Buwenge M, Nguyen NP, Farioli A, Schiavina R, Catucci F, Deodato F, Fionda B, Frascino V, Macchia G, Ntreta M, Padula GDA, Arcelli A, Cammelli S, Rambaldi GZ, Cilla S, Valentini V and Morganti AG: Tailored postoperative treatment of prostate cancer: Final results of a phase I/II trial. Prostate Cancer Prostatic Dis 21(4): 564-572, 2018. PMID: 30038390, DOI: 10.1038/s41391-018-0064-7

27 Kovács G, Tagliaferri L and Valentini V: Is an interventional oncology center an advantage in the service of cancer patients or in the education? The gemelli hospital and interacts experience. J Contemp Brachytherapy 9(6): 497-498, 2017. PMID: 29441092. DOI: $10.5114 /$ jcb.2017.72603

28 Buwenge M, Deodato F, Macchia G, Siepe G, Zhao X, Valicenti RK, Cilla S, Alitto AR, Ntreta M, Bisello S, Mantini G, Valentini V, Morganti AG and Cammelli S: Radiotherapy plus gnrh analogue versus high dose bicalutamide: A case control study. Anticancer Res 39(11): 6373-6378, 2019. PMID: 31704870. DOI: $10.21873 /$ anticanres. 13850

29 van Leeuwen CM, Oei AL, Crezee J, Bel A, Franken NAP, Stalpers LJA and Kok HP: The alfa and beta of tumours: A review of parameters of the linear-quadratic model, derived from clinical radiotherapy studies. Radiat Oncol 13(1): 96, 2018. PMID: 29769103. DOI: 10.1186/s13014-018-1040-z

30 Common terminology criteria for adverse events (CTCAE) । protocol development I ctep. Available at: https://ctep.cancer.gov/ protocolDevelopment/electronic_applications/ctc.htm

31 Alonzi R: Functional radiotherapy targeting using focused dose escalation. Clin Oncol 27(10): 601-617, 2015. PMID: 26456478. DOI: $10.1016 /$ j.clon.2015.06.015
32 Feutren T and Herrera FG: Prostate irradiation with focal dose escalation to the intraprostatic dominant nodule: A systematic review. Prostate Int 6(3): 75-87, 2018. PMID: 30140656. DOI: 10.1016/j.prnil.2018.03.005

33 Nestle U, Weber W, Hentschel M and Grosu A-L: Biological imaging in radiation therapy: Role of positron emission tomography. Phys Med Biol 54(1): R1-R25, 2009. PMID: 19060363. DOI: 10.1088/0031-9155/54/1/R01

34 Ellis RJ, Zhou H, Kim EY, Fu P, Kaminsky DA, Sodee B, Colussi V, Vance WZ, Spirnak JP, Kim C and Resnick MI: Biochemical disease-free survival rates following definitive lowdose-rate prostate brachytherapy with dose escalation to biologic target volumes identified with spect/ct capromab pendetide. Brachytherapy 6(1): 16-25, 2007. PMID: 17284381. DOI: $10.1016 /$ j.brachy.2006.11.002

35 Zamboglou C, Thomann B, Koubar K, Bronsert P, Krauss T, Rischke HC, Sachpazidis I, Drendel V, Salman N, Reichel K, Jilg CA, Werner M, Meyer PT, Bock M, Baltas D and Grosu AL: Focal dose escalation for prostate cancer using 68ga-hbed-cc psma pet/ct and mri: A planning study based on histology reference. Radiat Oncol 13(1): 81, 2018. PMID: 29716617. DOI: 10.1186/s 13014-018-1036-8

36 Grey A and Ahmed HU: Multiparametric ultrasound in the diagnosis of prostate cancer. Curr Opin Urol 26(1): 114-119, 2016. PMID: 26555694. DOI: 10.1097/MOU.0000000000000245

37 Zhang M, Tang J, Luo Y, Wang Y, Wu M, Memmott B and Gao J: Diagnostic performance of multiparametric transrectal ultrasound in localized prostate cancer: A comparative study with magnetic resonance imaging. J Ultrasound Med 38(7): 1823-1830, 2019. PMID: 30561768. DOI: 10.1002/jum.14878

38 Tanderup K, Pötter R, Lindegaard JC, Berger D, Wambersie A and Kirisits C: Ptv margins should not be used to compensate for uncertainties in 3d image guided intracavitary brachytherapy. Radiother Oncol 97(3): 495-500, 2010. PMID: 20888055. DOI: $10.1016 /$ j.radonc 2010.08 .021

39 Mantini G, Tagliaferri L, Mattiucci GC, Balducci M, Frascino V, Dinapoli N, Di Gesù C, Ippolito E, Morganti AG and Cellini $\mathrm{N}$ : Effect of whole pelvic radiotherapy for patients with locally advanced prostate cancer treated with radiotherapy and longterm androgen deprivation therapy. Int J Radiat Oncol Phys 81(5): e721-e726, 2011. PMID: 21277100. DOI: 10.1016/ j.ijrobp.2010.12.003

40 Ippolito E, Cellini N, Digesù C, Cilla S, Mantini G, Balducci M, Di Lallo A, Deodato F, Macchia G, Massaccesi M, Mattiucci GC, Tagliaferri L, Piermattei A, Cuscunà D and Morganti AG: Postoperative intensity-modulated radiotherapy with simultaneous integrated boost in prostate cancer: A doseescalation trial. Urol Oncol Semin Orig Investig 31(1): 87-92, 2013. PMID: 21458315. DOI: 10.1016/j.urolonc.2010.10.005

41 Macchia G, Deodato F, Cilla S, Torre G, Corrado G, Legge F, Gambacorta MA, Tagliaferri L, Mignogna S, Scambia G, Valentini V, Morganti AG and Ferrandina G: Volumetric intensity modulated arc therapy for stereotactic body radiosurgery in oligometastatic breast and gynecological cancers: Feasibility and clinical results. Oncol Rep 32(5): 2237-2243, 2014. PMID: 28794640. DOI: 10.3892/or.2014.3412

42 Porreca A, Noale M, Artibani W, Bassi PF, Bertoni F, Bracarda S, Conti GN, Corvò R, Gacci M, Graziotti P, Magrini SM, Mirone V, Montironi R, Muto G, Pecoraro S, Ricardi U, Russi E, Tubaro A, Zagonel V, Crepaldi G and Maggi S: Disease- 
specific and general health-related quality of life in newly diagnosed prostate cancer patients: The pros-it cnr study. Health Qual Life Outcomes 16(1): 122, 2018. PMID: 29898750. DOI: 10.1186/s12955-018-0952-5

43 Frakulli R, Cammelli S, Guido A, Arcelli A, Fuccio L, Ferioli M, Mattiucci GC, Cellini F, Macchia G, Deodato F, Cilla S, Farina E, Valentini V, Padula GDA, Morganti AG and Galuppi: Ep-1475: Brachytherapy boost after chemoradiation in anal cancer: A systematic review. Radiother Oncol 127: S800, 2018. PMID: 30038645. DOI: 10.1016/S0167-8140(18)31784-5

44 Autorino R, Tagliaferri L, Campitelli M, Smaniotto D, Nardangeli A, Mattiucci GC, Macchia G, Gui B, Miccò M, Mascilini F, Ferrandina G, Kovacs G, Valentini V and Gambacorta MA: Eros study: Evaluation between high-dose-rate and low-dose-rate vaginal interventional radiotherapy (brachytherapy) in terms of overall survival and rate of stenosis. J Contemp Brachytherapy 10(4): 315-320, 2018. PMID: 30237815. DOI: $10.5114 /$ jcb.2018.77953

45 Tagliaferri L, Manfrida S, Barbaro B, Colangione MM, Masiello V, Mattiucci GC, Placidi E, Autorino R, Gambacorta MA, Chiesa S, Mantini G, Kovács G and Valentini V: Mithra multiparametric $\mathrm{mr} / \mathrm{ct}$ image adapted brachytherapy (mr/ct-iabt) in anal canal cancer: A feasibility study. J Contemp Brachytherapy 5: 336-345, 2015. PMID: 26622238. DOI: $10.5114 /$ jcb.2015.55118

46 Tagliaferri L, Kovács G, Aristei C, De Sanctis V, Barbera F, Morganti AG, Casà C, Pieters BR, Russi E, Livi L, Corvò R, Giovagnoni A, Ricardi U, Valentini V, Magrini SM and Italian Radiation Oncology Schools Dot: Current state of interventional radiotherapy (brachytherapy) education in italy: Results of the interacts survey. J Contemp Brachytherapy 11(1): 48-53, 2019. DOI: $10.5114 /$ jcb.2019.83137

47 Tagliaferri L, Pagliara MM, Boldrini L, Caputo CG, Azario L, Campitelli M, Gambacorta MA, Smaniotto D, Frascino V, Deodato F, Morganti AG, Kovács G, Valentini V and Blasi MA: Interacts (interventional radiotherapy active teaching school) guidelines for quality assurance in choroidal melanoma interventional radiotherapy (brachytherapy) procedures. J Contemp Brachytherapy 3: 287-295, 2017. PMID. 28725254. DOI: $10.5114 /$ jcb.2017.68761

48 Alitto A, Gatta R, Vanneste B, Vallati M, Meldolesi E, Damiani A, Lanzotti V, Mattiucci G, Frascino V, Masciocchi C, Catucci F, Dekker A, Lambin P, Valentini V and Mantini G: Prodige: Prediction models in prostate cancer for personalized medicine challenge. Future Oncol 13(24): 2171-2181, 2017. PMID: 28758431. DOI: $10.2217 /$ fon-2017-0142
49 Tagliaferri L, Pagliara MM, Masciocchi C, Scupola A, Azario L, Grimaldi G, Autorino R, Gambacorta MA, Laricchiuta A, Boldrini L, Valentini V and Blasi MA: Nomogram for predicting radiation maculopathy in patients treated with ruthenium-106 plaque brachytherapy for uveal melanoma. J Contemp Brachytherapy 9(6): 540-547, 2017. PMID: 29441098. DOI: 10.5114/jcb.2017.71795

50 Dinapoli N, Alitto AR, Vallati M, Autorino R, Gatta R, Boldrini L, Damiani A, Mantini G and Valentini V: RadioBio data: A moddicom module to predict tumor control probability and normal tissue complication probability in radiotherapy. In: Proceedings of the $9^{\text {th }}$ International Joint Conference on Biomedical Engineering Systems and Technologies 4: 277-281, 2019. DOI: $10.5220 / 0005693502770281$

51 Ippolito E, Guido A, Macchia G, Deodato F, Giaccherini L, Farioli A, Arcelli A, Cuicchi D, Frazzoni L, Cilla S, Buwenge M, Mantini G, Alitto AR, Nuzzo M, Valentini V, Ingrosso M, Morganti AG and Fuccio L: Predictive factors of late-onset rectal mucosal changes after radiotherapy of prostate cancer. In Vivo 31(5): 961-966, 2017. PMID: 28882966. DOI: 10.21873/ invivo. 11154

52 Tagliaferri L, Budrukkar A, Lenkowicz J, Cambeiro M, Bussu F, Guinot JL, Hildebrandt G, Johansson B, Meyer JE, Niehoff P, Rovirosa A, Takácsi-Nagy Z, Boldrini L, Dinapoli N, Lanzotti V, Damiani A, Gatta R, Fionda B, Lancellotta V, Soror T, Monge RM, Valentini V and Kovács G: Ent cobra ontology: The covariates classification system proposed by the head \& neck and skin gec-estro working group for interdisciplinary standardized data collection in head and neck patient cohorts treated with interventional radiotherapy (brachytherapy). J Contemp Brachytherapy 10(3): 260-266, 2018. PMID: 30038647. DOI: $10.5114 /$ jcb.2018.76982

53 Preliminary data analysis in healthcare multicentric data mining: A privacy-preserving distributed approach - learning \& technology library (learntechlib). Available at: https:// www.learntechlib.org/p/182311 [Last accessed June 13, 2019]

Received January 17, 2020

Revised January 28, 2020

Accepted February 3, 2020 